\title{
Using Causal Mapping in the Analysis of Semi-structured Interviews
}

\author{
Igor Pyrko and Viktor Dörfler \\ University of Strathclyde
}

\section{Paper intended for the $\mathbf{7 8}^{\text {th }}$ Annual Meeting of the Academy of Management, Chicago, IL}

\begin{abstract}
In this paper we systematize Eden and Ackermann's approach to causal mapping as a technique for analyzing semi-structured interviews. By doing so, we aim to popularize causal mapping as an accessible, yet structured and formalized, method that can be used in a variety of studies within the broad organization and management research. In our discussion we characterize this approach to causal mapping as being grounded in Kelly's 'Theory of Personal Constructs'. Following Kelly's work, causal mapping seeks to represent some aspects of a person's thoughts about a given problem in question. On this basis, causal mapping, which is employed to work with different interviewees' individual maps carefully merged together, helps to enable an intersubjective position from where the interrelationships, and feedback dynamics, between elements of interview material can be explored. Thereby, while causal mapping can be a good way of surfacing aspects of the available interview material which could not be accessed by other methods, it can be used in combination with more traditional methods such as thematic analysis or narrative analysis. As a result, we argue, not only does causal mapping offer a structured approach to qualitative coding, but it lends itself well to adaptation in new areas of study where it has not been applied so far.
\end{abstract}

Key words: interviews, causal mapping, cognitive mapping, qualitative analysis 


\section{INTRODUCTION}

In qualitative studies of management, interviews are a popular way of collecting research data in organizational settings. Today's society has been labelled by some as an 'interview society' where interviews are a pervasive form of learning about the world (Atkinson \& Silverman, 1997). The popularity of interviews as a source of data about management and organizations has translated into a rich coverage of this method in methodological literature, including the work which address interviews with respect to reflexive interpretation (Alvesson, 2003, 2011), sampling (Saunders \& Townsend, 2016), data collection (Bourne \& Jenkins, 2005), or managing the interview situation (Dundon \& Ryan, 2010; Mittereder, Durow, West, Kreuter, \& Conrad, 2017). These contributions follow the developments in qualitative research more broadly, including an appreciation of the pluralism of philosophical standpoints which influence how the interviews are applied and made sense of (Cunliffe, 2011; Pratt, 2009).

However, despite the ubiquity of the use of interviews as a research method, there is space for improvement, primarily by developing better ways of analyzing the collected interview material. The most commonly used techniques typically mentioned by textbooks on business research methods (Easterby-Smith, Thorpe, \& Jackson, 2015; Saunders, Lewis, \& Thornhill, 2015) include a deductive content analysis which tends to be guided by pre-specified hypothesis or, at least, coding categories, as well as more inductive variants of thematic analysis (Gioia, Corley, \& Hamilton, 2013; Gioia \& Pitre, 1990). Further approaches include, for example, narrative analysis which attends to exploring the collected stories (Boje, 1995, 2003), and discourse analysis which looks at how language is used in local contexts (Cunliffe, 2008; Phillips, Sewell, \& Jaynes, 2008). However, it appears that none of the approaches is specifically focused on capturing and analyzing interdependencies between the (first or second order) themes of the coded material, causal 
relations, and feedback structures in a systematic way. Also, the coding process, particularly with respect to thematic analysis, can be daunting and arbitrary on the part of the researcher.

In this paper we seek to develop the existing portfolio of approaches to working with qualitative material by outlining a method for analyzing semi-structured interviews using a causal mapping technique. Our contribution draws on the particular approach to causal mapping developed over the last two decades by Eden and Ackermann and their colleagues (Ackermann \& Eden, 2011a; Paroutis, Franco, \& Papadopoulos, 2015; Shaw, Smith, \& Scully, 2017). Although Eden and Ackermann's approach has been successful both in research practice, there still appears to be space for widening its use in organization and management studies. In the Cambridge Handbook of Strategy as Practice, Langley (2015: 122) describes this approach as 'the magic' that may be seen as somewhat inaccessible and difficult to learn. In relation to this critique, in our discussion not only do we explain how this technique can be used for working with interview material, but we also address the methodological and philosophical considerations involved in using this approach.

Eden and Ackermann's approach to causal mapping has proved itself as being effective in revealing insights based on causal relationships and feedback dynamics which emerge from the interdependencies within the collected data, and so it allows exploring key themes and patterns (Bryson, Ackermann, Eden, \& Finn, 2004; Eden, Ackermann, \& Cropper, 1992; Shaw, Ackermann, \& Eden, 2003). So far, the main focus of this approach has been on the analysis of causal map models and data logs (Ackermann \& Eden, 2011b; Ackermann, Eden, \& Pyrko, 2016; Tavella \& Franco, 2015), as well as secondary sources (Shaw et al., 2017). Meanwhile, this method has not been elaborated in a focused way as an approach to working with interview material, although many examples of use exist (for example see: Eden \& Huxham, 2001; Pyrko, Dörfler, \& 
Eden, 2017). Thus, while we build on the established method of working with causal maps, we demonstrate its application with regards to conducting and analyzing semi-structured interviews, and we discuss the methodological and philosophical considerations of using this technique in qualitative research.

In order to present the method in a holistic way, this paper is structured as follows. Firstly, we describe in more detail the characteristics of cognitive mapping which focuses on mapping an individual's thoughts about a given question or problem, because it is conceptually grounded (Kelly, 1955) and well-elaborated in the literature (Eden, 1988, 1992a; Eden, Jones, \& Sims, 1983). We then build on the principles of cognitive mapping as we review Eden and Ackermann's approach to causal mapping, which focuses on elucidating a group's understanding of a problem, and we note its different application areas. We use this review to elaborate an approach to using causal mapping in the analysis of interviews, where a causal map informs the coding of interviews, and the map itself is revised in a cyclical manner. We illustrate the application of this approach with examples stemming from a qualitative study in the National Health Service Scotland. We go on to discuss the advantages and limitations of causal mapping. We also address the ontological and epistemological considerations of using this method with respect to different research designs, with particular focus on the matters of change, knowledge, and reality. Finally, we conclude our argument by suggesting directions for future developments and application of this method in organization and management research. 


\section{COGNITIVE MAPPING AS THE FOUNDATION FOR CAUSAL MAPPING}

\section{Cognitive mapping and causal mapping: a family of techniques}

Cognitive mapping and causal mapping are an established family of techniques (Hodgkinson, Maule, \& Bown, 2004) which includes both quantitative (Clarkson \& Hodgkinson, 2005) and qualitative approaches (Huff, 1990; Jackson \& Trochim, 2002; Jenkins, 2002; Laukkanen, 1994; Nicolini, 1999; Paroutis et al., 2015; Swan, 1997). In an interview situation, cognitive mapping refers to mapping an individual interview, while causal mapping concentrates on working with multiple interviews from different people in one map. We note that related approaches to cognitive mapping and causal mapping have been formulated before for working with interviews, such as applying multidimensional scaling analysis to concepts gathered through open-ended survey responses (Jackson \& Trochim, 2002), or using a laddering interview method to elicit personal values (Bourne \& Jenkins, 2005). However, in this paper we take a somewhat different angle.

In our discussion we build on Eden and Ackermann's approach because it offers a set of sophisticated tools and techniques for managing messy qualitative material without losing on its richness - an attention is paid to the idiographic nature of interview data and without resorting to treating the data as if it were nomothetic (Eden, 2004). We therefore aim to systematize Eden and Ackermann's approach to causal mapping as an accessible and flexible method for analyzing semistructured interviews that can be highly relevant to a broad management research audience. However, before characterizing causal mapping, in this section we first describe Eden and Ackermann's view of cognitive mapping because the former builds on the latter conceptually. 


\section{Origins of cognitive mapping: the Theory of Personal Constructs}

As discussed by Jenkins (2002), Huff (1990) categorized different approaches to cognitive mapping, including approaches focused on calculating the frequency of concepts occurring in the empirical material, exploring how and why study participants allocate concepts into selected categories, or examining the underlying structures between concepts by attending to their linguistic interrelationships. However, with respect to both cognitive mapping and causal mapping, in this paper we focus on the work of Eden and Ackermann and their colleagues. This approach, we argue, can be used as good way of analyzing semi-structured interviews by gaining insights from sophisticated exploration of causal relationships between the concepts in the interview material. Also, for simplicity, each time in this article we refer to cognitive mapping or causal mapping, we assume Eden and Ackermann's approach.

The characteristic feature of cognitive mapping is that it originally sought to operationalize Kelly's (1955) ‘Theory of Personal Constructs'. As discussed by Eden and Jones (1984) and Eden (1988), according to Personal Construct Theory, individuals are seen as problem solvers who learn about the world, and anticipate the future, by establishing contrasts and similarities with regards to the things that they know and learn about (e.g. Susan and Angela are similar to each other both being girls in contrast to Peter, who is a boy, while Angela and Peter are similar to each other both being blonds in contrast to Susan who is a brunette). The contrasts and similarities are made through explanations of why certain events have happened, or by formulating their personal hierarchies of meanings. The postulate of anticipating future by making sense of the world is elaborated by 11 corollaries, three of which are particularly relevant to both cognitive mapping and causal mapping. The 'individuality' corollary states that people's constructs, and so the explanations, of (even the same) events can be different. The 'sociality' corollary means that 
effective interactions between people depend on the extent to which they can understand one another's construct systems. And the 'commonality' corollary signifies that commitment and consensus from a team of people requires that they establish a shared way of construing future events. As a result, based on these three corollaries, it can be said that every person has their own system of constructs (mental map) which can be "elaborated" or adapted when exposed to other peoples' construct systems - and so may result in changing their minds.

In addition, Kelly introduced a method of operationalizing his theory in the form of a repertory grid technique (Bonarius, Holland, \& Rosenburg, 1981; Brown, 1992; Fransella \& Bannister, 1977). This technique, which is aimed at eliciting people's personal construct systems and exploring contrasts and similarities between their constructs, has been popularized in the academic research (as seen in: Easterby-Smith, Thorpe, \& Holman, 1996; Wright, 2008). The application of repertory grid technique (Armstrong \& Eden, 1979) also inspired the development of cognitive mapping 'from the perspective of Kelly', which, however, was designed to add more richness to the resulting models than the former, and so allow more space for participants' involvement in the process of modelling (Eden, 1988).

\section{Using cognitive mapping: understanding a problem}

Cognitive mapping is employed to capture, by a mapper, some aspects of a person's construct system, and, on the basis of reflecting on the elucidated maps, help participant develop their understanding of a problem in question (Eden, 1988, 1992a). This method is in sympathy with Weick's (1995) take on organizational sensemaking, and so it assumes that, as part of people's everyday practices, articulation, thinking, and doing cannot be separate. In other words, the articulation of a person's construct system always remains inevitably 'out of step' of that person's thinking in-situ, as in the famous assertion 'I don't know what I think until I hear what I say'. 
Therefore, cognitive maps are not intended to capture a complete representation of a person's construct system, rather a part of it localized at a particular problem, at the time when the map is created. As Eden (1992a: 262) notes:

“(...) cognitive maps can be seen as a picture or visual aid in comprehending the mappers' understanding of particular, and selective, elements of the thoughts (rather than thinking) of an individual, group or organization. They may also be seen as a representation that is amenable to analysis by both the mapper and others."

Nevertheless, cognitive maps, as representations of those aspects of a person's thoughts which are of relevance to a given question or problem, can play a very useful role in representing, communicating and exploring the empirical material. The maps, as representations, become relatively independent from the person whose thoughts have been mapped as well as from the mapper; therefore they become transitional objects which can be edited along with the person's change of understanding (de Geus, 1988; Winnicott, 1953) and analyzed in themselves (which aspect will be very important for the subsequent discussion). This way, cognitive maps can serve as tools for problem structuring, decision making, and negotiation (Eden, 1988, 1992a).

An example of a simple cognitive map is shown in Figure 1. In this example, one of the authors mapped his intentions of preparing an article for the Academy of Management annual meeting. He first entered a statement in which he stated what he wanted to do - in this case 'write a paper for AoM rather than miss the submission date' (statement 1). The statements which are linked to statement 1 explain how this action could be achieved: by working all weekends rather not working during weekends, and by using the analysis from existing research. There is also a negative link (marked with a minus sign) coming from statement 7 (go on a desired trip to Portugal) 
to statement 1 because if he decides to go on the trip, he will most likely miss the submission deadline - the trip therefore has to wait until summer. Meanwhile, the links going from statement 1 explain why the author wants to write the paper, or what is achieved by writing the paper: so that he can attend the conference (statement 3), and have useful material to draw on for future journal publications (statement 20). These two actions in turn to lead to more general, desired outcomes (marked by boxed statements) such as meet colleagues from the academic community, or improve the existing publications portfolio. In addition, statement 8 demonstrates the ramifications of missing the opportunity to submit the paper through negative links: it will not be possible to attend the conference and to have a material to draw on in future journal publications.

Insert Figure 1 about here

Thus, the cognitive map in Figure 1 introduces the logic used in mapping an individual's account. As each person's cognitive map, even when representing the same problem, is inevitably different, cognitive mapping demonstrates the 'individuality' corollary described above. The two remaining corollaries, 'sociality' and 'commonality', while also relevant to cognitive mapping for example in a consultant - client relationship, are particularly evident in relation to causal mapping. The reason for this is that causal mapping captures multiple perspectives, accounting for different individuals with separate construct systems, in one 'shared' map. And because capturing multiple perspectives is of high interest to qualitative research, causal mapping is employed as the basis for the technique of collecting and analyzing interview material presented in our discussion. 


\section{EDEN AND ACKERMANN'S APPROACH TO CAUSAL MAPPING}

\section{Causal mapping: establishing an intersubjective position within groups}

While cognitive mapping is aimed at working with an individual's account of a problem, causal mapping is used by a researcher or a consultant to surface selected elements of a group's understanding. Causal mapping builds on cognitive mapping, but in contrast to cognitive mapping it seeks to map the contributions of a group to see how individuals' thoughts complement, reinforce, or contradict one another. In an interview situation causal mapping does not necessarily entail a group interview or a focus group situation, because maps obtained from individual interviews (cognitive maps) can be merged together and so form a shared causal map.

Nonetheless, the typical application of causal mapping is to facilitate meetings in which participants are assisted in building a shared causal map which represents multiple accounts. All of the participants' contributions are elaborated collectively and linked with one another by the group. Thus, the resulting shared, causal map no longer represents any particular person's thoughts. Instead, the map becomes a device for negotiating a consensus as part of which different participants' contributions are synthesized into a new conceptualization of the future course of actions (Bryson, Ackermann, \& Eden, 2014; Bryson et al., 2004). Here it becomes particularly important that the map becomes a transitional object that can be referred to, making it possible to elaborate particular contributions without addressing directly the person whose contribution is being elaborated. Throughout the process of building a casual map, by visually representing each person's thoughts on the map and by effectively separating a person from the problem, participants are supported in both talking and listening. And as the group members come to appreciate one 
another's' individual understandings, it is easier for them to establish an intersubjective position on the problem in question (Eden, Jones, Sims, \& Smithin, 1981).

It should also be noted that causal mapping is not merely about producing 'word-andarrows' diagrams, but it is governed by a set of formalisms which allows for analysis of rich and messy qualitative material (Bryson et al., 2014; Bryson et al., 2004). Particular attention is paid to actions and events and to how they may affect one another. This allows to understand better the relationships between the different constructs in the causal map, and to explore possibly insightful patterns, dynamics, inconsistencies, or missing links (Eden et al., 1992). As a result, causal mapping has proved itself as an effective consultancy and research technique for working with teams. The process of casual mapping is additionally supported when a specialized computer program or a group support system ${ }^{1}$ are utilized for building and analyzing causal maps, which improves the efficiency of adding contributions, increases the speed and accuracy of analysis, and, importantly, ensures anonymity (Ackermann \& Eden, 2011b; Ackermann, Franco, Gallupe, \& Parent, 2005; Franco \& Rosenhead, 2001).

\section{Applications of causal mapping in organization and management research}

Due to the advantages of using causal mapping in group settings, it has found itself diverse applications in the organization and management literature. And, as causal mapping lends itself well for engaging directly with management teams, causal mapping studies often follow the action research design (Eden \& Huxham, 1996, 2002).

\footnotetext{
${ }^{1}$ Group Explorer is a Group Support System that facilitates high group productivity and the real time construction of causal maps. The software utilizes Causal Mapping software (Decision Explorer from Banxia.com, and Group Explorer is freely available).
} 
Perhaps the most prominent application of causal mapping has been in the studies of strategy and strategy making with executive teams. In those studies, facilitated causal mapping workshops have contributed to a better understanding of strategy as a social process as part of which consensus about the firms' future needs to be negotiated effectively by the management team (Eden, 1992b; Eden \& Ackermann, 2001). Practical contributions of these studies include mapping the management of stakeholders (Ackermann \& Eden, 2011c), portraying organizational purpose as a system of goals (Eden \& Huxham, 2001), sharpening the understanding of core competencies and distinctive competencies (Eden \& Ackermann, 2000, 2010), or formulating structured forums for productive strategic work with management teams (Ackermann \& Eden, 2011a).

Other applications of causal mapping have been in risk management where risks are presented as networks of risks which interact with one another (Ackermann, Eden, Williams, \& Howick, 2007; Ackermann, Howick, Quigley, Walls, \& Houghton, 2014; Pyrko, Howick, \& Eden, 2017), structuring of messy problems, (Eden, 2004; Eden \& Ackermann, 2006), or in project management to understand better the nature of complex projects (Ackermann \& Alexander, 2016; Ackermann \& Eden, 2005). Causal mapping has also been used effectively in the preliminary stages of studies aimed at constructing system dynamics models which, through capturing feedback dynamics, build the ground for quantitative analysis (Eden, 1994; Howick \& Eden, 2001; Williams, Ackermann, \& Eden, 2003).

Those studies often concentrate on causal map models as the primary source of data, and for this reason causal mapping is often associated with the management science literature where modelling rather than interview data is of interest. Meanwhile, the interview technique which we present in this paper does not take causal maps as the main point of reference as part of conducted 
research. Instead, we draw on the established causal mapping technique, formulated in the reviewed studies, to demonstrate how causal map models can support interview research and analysis. This way we expect to broaden the audience for causal mapping method and transfer its advantages to new areas of organization and management research.

\section{Mapping with software support}

The cognitive mapping and causal mapping approaches described above do not necessarily need software support - however the use of software is rather useful. The mapping process can be made much simpler and more effective if an appropriate software tool is used; this is particularly clear in the case of large maps with hundreds of links and statements (Ackermann \& Eden, 2011a; Bryson et al., 2014; Bryson et al., 2004). Originally, cognitive maps were primarily hand-drawn on paper (and this approach still remains in use). Meanwhile in particular casual mapping was supported with the so called 'oval mapping', which utilizes a variant of post-its that are ovalshaped (to avoid constructing tables rather than maps). Oval maps can be placed on large empty surfaces and arrows can be drawn between them. What is immediately obvious, is the difficulty to make changes once the arrows are drawn, which makes the map more problematic to use as a transitionary object that can be modified at any time. Oval maps are easy to move around, but the arrows are not. In contrast, it is easy to rearrange maps on computer screens.

In this paper, for the purpose of working with interview material, we use the Decision Explorer software which is equipped with powerful analytical features. It is a tool which allows to construct causal maps on the computer screen, and break it down into smaller segments while keeping the original content. The software can also be used to explore key patterns in the data based on, for example, the position of the statements in the map, the density of links around statements, the number of chains of outcomes leading from the statements, or the identification of 
positive and negative feedback loops within chains of argument. Therefore, while the examples shown in this discussion are with the use of software, it is not a requirement to use the software to employ the technique presented in our discussion.

\section{RESEARCH IN THE NATIONAL HEALTH SERVICE SCOTLAND}

Our discussion about using causal mapping in collecting and analyzing interview material is supported with examples from a case study in the National Health Service (NHS) in Scotland. The study was conducted over a period of two years across different parts of the NHS Scotland, and its aim was to explore how different, local Communities of Practice (CoPs) learn from one another across organizational boundaries. CoPs are understood as groups of people who learn from each other regularly because they care about the same real-life problems (Wenger, 1998). Notably, the NHS Scotland is not a single organization but rather a multi-organization health system consisting of 14 regional 'health boards' which all exercise a fair level of autonomy and a degree of mutual competition.

The research participants were healthcare professionals in the medical areas of sepsis and dementia who had interest in CoPs and improving patient care through peer learning. The research comprised 29 one-hour long semi-structured interviews and loose conversations supplemented by observations of participant interactions, as well as by a review of relevant documents and websites. In addition, interviews were conducted with coordinators of formal 'learning networks' which, among others, included practitioners from the two medical areas. For organizing the interviews a combination of purposive and 'snowball sampling' was used (Biernacki \& Waldorf, 1981; Teddlie \& Yu, 2007). The interviews included topics about learning in CoPs, organizational learning culture, and possible ways of developing CoPs in the workplace. 
The interviews were coded and analyzed using a qualitative causal mapping method. The reason for adopting this method was that it is well suited for working with rich, idiographic qualitative empirical material. The produced graphs are causal maps consisting of short statements (interview quotes) which are connected by unidirectional arrows signifying 'may lead to' relationship (Eden, 1992a; Eden et al., 1992; Hodgkinson et al., 2004). These causal maps are based on the interview material, they do not extend the interview material in any way, and they should represent, to the researcher's best ability, the interviewee's natural language faithfully, rather than paraphrase or summarize it.

Three phases comprised the data analysis in this research. In the first phase, causal maps were constructed using the Decision Explorer causal mapping software. The captured statements from the recorded interviews were mostly action-oriented, where interviewees were implying that something needed to be done to change the CoP, illustrating the dynamic 'worlds' of CoP members and their interpretations of their idiosyncratic worlds (Bryson et al., 2014). The final map, including the merged material from all interviews, comprised 1869 interconnected statements.

In the second phase, the analytical features of the software allowed searches for interesting patterns and key themes in the empirical material, including positive and negative feedback loops, tightly interwoven clusters of statements, and 'central' (highly interlinked) statements. The relevance of the candidate key themes to our research question was evaluated and challenged in the discussions between the researchers, and also with respect to the existing CoP literature. In such sense, once the patterns in the casual maps were identified, they were assessed in a similar way as it is done when working exclusively with NVivo, as for example seen in Hibbert et al. (2016) or Siedlok et al. (2015). 
In the third phase, the identified patterns from causal maps served as the basis for constructing a hierarchy of nodes in NVivo where the interviews transcripts were managed. As NVivo contained the complete transcripts, all the quotes used in the maps could be located within the interview text. In addition to this, NVivo enabled a check that nothing important or relevant had been missed. As NVivo offers clear and practical transition and comparison between the transcripts of the different interviews, the consistency in context was checked when merging the maps of the individual interviews (besides examining the direct links in the individual maps). This is very important, as two statements in different interviews should only be merged if was clear that the two interviewees meant the same. Furthermore, NVivo was used for managing the longer quotes. Thus, the two models in Decision Explorer and NVivo are complementary, displaying the same meaning from slightly different perspectives and offering different features. In this sense, the two models were used together to inform the structure of our discussion. By doing so, as discussed by Feldman (2004: 298), we did not intend to use our data 'to prove but to exemplify', and our aim was to consider how our 'narrow segment of the actions and ideas present in the case can help us arrive at a number of generalizable inferences.

\section{CAPTURING INTERVIEW MATERIAL AS A CAUSAL MAP}

\section{Mapping interview material}

Building on the examples from the research on CoPs in the NHS Scotland, we now present how causal mapping can be used to work with interview material. We first talk about collecting the interview material with casual mapping, and subsequently we proceed to the discussion of analysis. In the research in the NHS Scotland, causal mapping was used to map semi-structured interviews with the expectation that it would allow to add more rigor and clarity to thinking about 
the messy problems surrounding CoPs, such as the issues of knowledge and learning across functional teams, organizational politics, or culture.

In this study, interviews were collected individually rather than in groups because the participants were employed in different hospitals and they were scattered across different parts of Scotland. Following the suggestions in the methodological literature (Easterby-Smith et al., 2015), during the interviews, notes were taken regarding the non-verbal cues which subsequently informed the analysis. The authors firstly created individual, cognitive maps based on the interviews with each participant, and only then the constructed maps were merged into one shared, causal map.

It is typically possible to construct cognitive maps in real-time during the interview situation, and even though the map tends to be messy at that point, it can indicate gaps or inconsistencies in the interviewee's argument, or things that the interviewee is not clear about, or things that the interviewer does not understand (Eden, 1988, 2004). Mapping interviews in realtime also allows to validate the maps with participants directly after the interview, and to spot possibly missing links and statements in the map. Such gaps in turn prompt the interviewer to ask relevant questions that might have not been asked otherwise.

However, in this study it was decided to create the maps after the interviews because at the beginning of the research the modeler was a relatively novice mapper. The interviews were transcribed by the researchers, and the maps were constructed by listening to the recorded interviews. Based on the experiences of the researcher of this study we suggest working with the audio or video recording without stopping rather than coding from the transcript. The reason for this is that it allows the modelers to immerse themselves into the recorded conversation, and pay 
attention to the non-verbal cues. The non-verbal cues, such as the tone of voice and combined with the notes taken earlier, helped to understand better the significance of various statements added to the map. In addition, following Eden and Ackermann's (2011a) approach, the mapper was attending mainly (but not exclusively) to the actions (e.g. train new staff, create a new product), and he was trying to link actions with one another based on the expressed causalities in the interview accounts (such as 'because', 'in order to', 'and so', etc.). Care was also taken to retain the natural language of the interviewees rather than paraphrase their contributions in order to retain the original meanings.

What may be misleading about cognitive mapping is that it may seem easy and intuitive at the outset because one can simply start entering the statements and connecting them together. Nevertheless if one does not follow the coding conventions (Ackermann, Eden, \& Cropper, 1990) then one can easily end up with a map which is not very useful and not amenable to analysis. As suggested by Eden et al. (1992), the inexperienced modelers often create maps that have too many links and too few nodes. For example, in the first attempts to produce the maps for the study in the NHS Scotland, the modeler was mapping roughly 35 statements per hour of interview, whilst after reworking his maps twice from scratch and considerably revisiting the causal mapping literature he was coding on average 70-100 statements per hour of interview. The explanation for this can be that, based on our research and teaching, inexperienced modelers tend to aggregate the statements and avoid mapping what they do not consider to be relevant. Such approach makes the map less useful because the very purpose of the map is to represent the problem in its full richness - the map should serve to understand the problem better without losing on its complexity (Eden, 2004). 


\section{Tidying and merging the maps}

Once the individual cognitive maps were constructed, they needed to be 'tided'. This involved: i) double-checking the wording of statements and the direction of arrows based on the interview material, ii) deleting summary arrows which explain the same chain of argument (e.g. delete $\mathrm{A} \rightarrow \mathrm{C}$ when there is already $\mathrm{A} \rightarrow \mathrm{B} \rightarrow \mathrm{C}$ ), iii) ensuring that the more specific statements lead to more general outcomes, and iv) 'tying up' links which do not have any outward links, but which are not general outcomes that are good in their own right. The researchers also included additional links and statements which reflected their own judgment regarding the interview material, as well as links and statements which represented the literature. However, those additional links and statements were coded with a different color so that they could be easily distinguished or, if needed, excluded from the rest of the material.

Subsequently, the cognitive maps were merged together into one shared, causal map. This involved merging statements which have similar wording and meaning. However, similar statements could only be merged when the links and statements around them were also related. In other words, only the statements with the similar context could be merged into one statement. This means that it was possible to have in the causal map two statements with the same wording, but with different context around them - and so they represented different interpretations of the same events. In addition, links were added between the cognitive maps based on i) the interview material, ii) the literature, and iii) the researchers' judgment - and those addition links were also color coded. It should also be noted that the process of merging the cognitive maps did not involve putting all the maps into the same computer view or a sheet of paper. Instead, the merging was done by noting the references to the other maps (i.e. shared links and statements) while working 
with individual maps, as otherwise the resulting 'complete' map would be far too large to be easily managed.

The final stage in tidying and merging the maps entailed forming a so-called 'tear-drop' structure (Figure 2) for key themes and patterns identified in the analysis which is described in the next sub-section. The segments of the casual map which represent key themes and patterns were moved to separate, smaller maps so that they were more manageable (while retaining the original links to the rest of the map as references). Those smaller maps were organized into a the 'teardrop' structure in which more specific statements are positioned in the bottom of the map, and they are directed towards the more general outcomes which are placed at the top of the map. This way it is easier to read and analyze the causal chains of arguments in a clear way.

Insert Figure 2 about here

\section{ANALYZING INTERVIEWS USING CAUSAL MAPPING}

The smaller segments of key themes and patterns have been identified through the analysis of causal maps in line with the established literature (Bryson et al., 2014; Bryson et al., 2004; Cropper, Eden, \& Ackermann, 1990; Eden, 2004; Eden et al., 1992). The analysis described in this section can in principle be performed manually. It must however be noted that with 50-60 or more statements such manual analysis become difficult and time-consuming, often leading to mistakes, and with a few hundred it is very difficult. As a result, with large maps the use of software may be necessary.

One type of analysis is central is central analysis, which refers to the identification of those statements which exercise the strongest influence in the model based on their causal links with the 
rest of the map. Central analysis can be illustrated with a metaphor of ripples in a pond, in which the biggest ripples are identified among a set of smaller ripples. In the reported research, an example of a statement with a high centrality score was statement 1221 'show value of the Community of Practice (CoP) site to potential members' (Figure 3). The chains of argument which drive statement 1221 indicate that, for example, in order for the action in statement 1221 to happen, it may be needed to build a group of core member of the CoP and so offer opportunities for sharing knowledge. It may also be needed to offer opportunities for professional development, and work on building people's confidence. In addition, it may be of particular interest to explore the outcomes of action 1221: people share knowledge regularly rather than only when they meet as a group with their leader (statement 1248), and the CoPs members do not talk (due to the minus sign near the causal arrow) by email rather than use the dedicated CoP website (statement 466). As a result, the map in Figure 3 shows clearly the interactions and mutual dependencies between actions mapped directly from the conducted semi-structured interview.

Insert Figure 3 about here

In addition to central analysis, there are also other types of analysis of causal maps. A similar type of analysis to central is domain analysis which entails counting the number of links around each concept in the map, and then ranking them from those with the highest number of links to those with the lowest number of links. Furthermore, with the use of software it is possible to run cluster analysis (the software partitions the data into segments based on the density of causal links between statements), or potent analysis which looks at how many of the selected outcomes are eventually hit by tails (statements without inward links - typically positioned in the bottom of the map). Also, of particular interest can be loop analysis which searches the causal map for 
feedback loops. Different types of feedback loops can be identified, including negative feedback loops (that stabilize relationships around a particular value) or positive feedback loops (that escalate, if they escalate towards a desired value, they are called virtuous loops, if towards an unwanted value, they are called vicious loops).

An example of a feedback loop is shown in Figure 4, and it says that healthcare practitioners communicate with one another by email rather than on the dedicated CoP website (statement 466), which leads to professional course leaders (who manage the CoP site) being disappointed with the members not using the dedicate website to talk, and so the CoP members have to explain to a representative of a Government their lack of participation, leading to decreasing trust of the CoP site, which means that the site is used at most as a communication tool but not to develop or explore real issues, which in turn reinforced the initial trigger in statement 466. This is an example of an escalating, self-reinforcing feedback loop which has negative ramifications both for the professional development course leaders and for the CoP members. Interestingly, the feedback loop could be broken by supporting and elaborating further the action in statement 1221 which has a negative link going to statement 466 , and which is by showing value of the $\mathrm{CoP}$ to potential members.

Insert Figure 4 about here

It therefore can be seen that causal mapping can be used effectively in the identification of key themes in pattern in the interview material. Also the structures of the maps which represent interviews provide valuable insights, as for example they can demonstrate missing links or inconsistencies in the interviewee's view of the problem. By validating the structures of the maps 
with the interviewees, either during or after the interview, can give another opportunity to elaborate the causal map further. The resulting themes from the casual map analysis can therefore inform thematic coding which can be transferred into NVivo, as thematic coding can represent the causal structures and interdependencies between statements in the causal map. By assigning interview text to the codes it is possible to validate further the structure of the maps an in iterative way. This way, casual mapping does not have to be seen as a replacement for thematic analysis, but causal mapping and thematic analysis can be used together to ensure a rigorous and systematic exploration of interview material.

\section{METHODOLOGICAL AND PHILOSOPHICAL CONSIDERATIONS OF USING}

\section{CAUSAL MAPPING}

Having described the technique of using causal mapping in collecting and analyzing interviews in the previous sections, in this section we now discuss the methodological and philosophical considerations with respect to the broader organization and management research. We first reflect on the advantages and limitations of applying causal mapping as a method of collecting and analyzing interviews. Subsequently, we discuss the philosophical considerations of using causal mapping. With respect to this discussion we argue that causal mapping can be adopted to the studies underpinned by various types of ontological and epistemological views as long as they accept at least some degree of relativism that is characteristic to Kelly's perspective on casual mapping.

\section{Advantages and limitations of causal mapping as a research method}

Based on the study in the NHS Scotland which has been drawn upon in this paper, it can be argued that causal mapping, as a technique for collecting and analyzing interviews, offers a 
number of advantages to researchers. Causal mapping offers a structured and systematic, yet at the same time flexible method for working with interview material, and so it provides considerable benefits to, for example, more traditional thematic analysis.

Causal mapping, as a technique, is structured and systematic because it is expected to adhere to the rules of mapping and analyzing interviews described in detail above. Hence, causal mapping can support researchers in developing thematic coding in a way which accounts for assumed interrelationships between the codes that are expressed in the interview material. This in turn allows to formulate a sharp coding structure for researchers who employ thematic analysis and who, for example, use the NVivo software. Moreover, causal maps, as visual representations of interview material, can be a good way of feeding back and validating the interview output with the interviewee.

At the same time, casual mapping is a flexible method because it allows to work with rich, messy interview material and preserving, at least as much as any other method, this richness. Large causal maps consisting of a few hundreds of links and statements can be conveniently explored using smaller 'views' (that is parts of the map in separate screens) with the aid of specialized software. By navigating between the smaller views which represent key themes and patterns within the context of a larger casual map, it is possible to explore interactions, inconsistencies, contradictions, and feedback between statements in the interview material. This method also enables reflexivity in the sense that reflexive comments from the interviewer/mapper can be explicitly included (Cunliffe, 2003). In addition, various other sources can be easily merged with the interview content, such as comments on the setting, mood, or preliminary study material. Because those additional sources can be included into different 'sets', including sets distinguished by different font style, they can be easily excluded from analysis when needed. 
There are, however, also limitations in using this method. Firstly, as with any other method, it requires an investment of time and effort on the part of the researcher, which may be significantly higher than with other qualitative methods. Treating causal mapping as the production of merely 'word and arrow' diagrams is likely to produce maps which are of little use and which are not amenable to the analysis described in this paper. Therefore, careful learning of the specific mapping conventions is necessary. Furthermore, causal mapping may be seen as an option, rather than a necessity, which forces researchers to spend a large amount of time on constructing and analyzing the map, while it might be considered sufficient to conduct traditional thematic coding. The situation is even more problematic if causal mapping is considered to be an add-on to the thematic or content analysis. It is therefore essential that the researchers recognize whether the causal structure offered by causal mapping is relevant and useful to the research in question.

\section{Causal mapping: measuring cognition?}

In The Palgrave Handbook of Organizational Change Thinkers, Hadjimichael (2017: 1366) criticizes Eden and Ackermann's approach to cognitive and causal mapping in the context of 'organizational change via philosophy and complexity'. Hadjimichael states that this approach is inadequate for researching organizational change because i) it assumes that "meaning is equated with information processing", ii) it tries to measure peoples' cognition, and iii) it sees "organizational change only as a matter of planning". These are three possible misconceptions of casual mapping which we address in this sub-section in order to help researchers position this method in the context of their own work.

As already stated above, cognitive and casual mapping do not seek to 'measure', or capture, peoples' cognition, but the purpose of these maps is to serve as useful points of reference, as simplified transitory objects, which help to explore some selected aspects of peoples' thoughts in 
relation to the problem in question. Knowledge is inherently personal, grounded in the 'tacit component', and it cannot be measured or fully articulated because "a wholly explicit knowledge is unthinkable" (Polanyi, 1966: 7). On this basis, causal maps serve to help in organizing, negotiating, and prioritizing peoples' selected thoughts. Meaning is developed through researchers' and participants' active interactions and modifications of the maps, as they make sense of the maps and as they change their minds, and not merely through 'information processing'. The mapping process is emergent as the mapper has to adjust to the interview situation and try to represent visually the interview material as faithfully as possible. Thus, when for example used in strategy development, causal maps are merely an intention for strategic change; causal maps are designed for emergence through further reiteration, discussions, and negotiations among the management team and their key stakeholders as part of gradual strategy implementation. Meanwhile, with regards to interviews, the resulting causal maps are imperfect, yet helpful, representations of the interview material which can be conveniently communicated, and so validated, with the interviewees.

Furthermore, it can be argued that anything that qualifies for 'studying' has at some point explicit verbal accounts of some sort - which means that they can be mapped. Thus, if causal mapping was essentially cognitivist, interviews in general should be rejected by anyone who opposes the cognitivist view - and interviews are a very popular research method in, for example, the practice studies of organizations. The thematic codes which can be developed based on the analysis of maps do not derive from measuring someone's cognition, but from careful exploration of verbal accounts, be it interview material or text. In addition to this, causal mapping does not influence the interview outcome except in as much as any social setting. In contrast, it helps to 
make the interviewer's influence more visible as the interviewer's proposed links and statements can be distinguished visually in the maps.

Thus, causal mapping is a flexible method which can be adopted in different types of qualitative studies. However, the studies which wish to adopt Eden and Ackermann's approach need to accept Kelly's subjective perspective on knowledge and reality, and so at least some degree of relativism and interpretivism has to be recognized. An example of studies which could make a good use of causal mapping are practice studies which tend to prefer ethnographic study design (Gherardi, 2012; Nicolini, 2013). With respect to practice studies, causal mapping can be applied not only to interviews abut also to notes from observations and analysis of secondary sources. Here the advantage of using causal mapping is therefore in managing rich empirical material and in exploration of that material in a systematic way.

Another example of a stream of research which could employ causal mapping could be the process view of organizations (Chia \& Holt, 2009; Hernes, 2014). If the interview situation is considered as a process, causal mapping comes as close as possible to process-oriented data collection through mapping the interview situation in-situ, just like a video or a voice recording. However, all criticism that applies to causal mapping from a process perspective will also apply to any ways of using interviews. Moreover, from the process perspective, instead of concentrating on actions, the mapper could focus on mapping organizational events and how those events unfold over time. And, if interviews were repeated the from time to time, then any changes observed can be indicated in the map as well.

Consequently, building on the flexible method of using causal mapping for analyzing semistructured interviews which has been systemized in this paper, future research can explore new areas of studies where this approach could be applied. New ways of mapping, coding, and 
analyzing material can be developed, depending on the philosophical and methodological requirements of the study in question and the philosophical position of the researcher. New sources of data can be combined in the maps. Therefore, while the method of causal mapping reported in this research is well-established, it offers promising paths for improvement and adaptation by researchers and consultants in various fields of organization and management research, and so enable casual mapping account for the increasingly pluralistic character this area of study.

\section{CONCLUSION}

Eden and Ackermann's approach to causal mapping has been described in this paper as a flexible and systematic method for collecting and analyzing interviews. While causal mapping has been applied to various types of studies, more work needs to be done to popularize this method beyond only management science, in the broad organization and management research. Causal mapping is a formalized technique which, as any research method, requires investment on the part of the researcher or consultant to learn appropriately. However, as evidenced in the paper, when the technique is followed carefully, it offers considerable advantages to researchers. Causal mapping can support interviewers during the interview, and after the interview, by helping to understand better the missing points as well as interrelationships between statements voiced by the interviewee. In addition, with respecting to coding the interview material, causal mapping can be a good way of developing a sharp coding structure that is developed in a systematic way. Hence, causal mapping can allow to shed 'a new light' on the available interview material in a way which is not possible with other types of analyzing qualitative data.

Furthermore, considering the continuous developments in the organization and management research, causal mapping offers new paths for methodological improvement and adaptation. Since qualitative research inevitably uses textual and verbal data, causal mapping can 
be utilized to analyze the empirical material in a fashion that is faithful to the study in question, such as practice studies, process studies, or studies of innovation and creativity. At a more fundamental level, using causal mapping in the analysis of interviews provokes debates about the relationships between knowledge and knowing, process and structure, cognition and practice. The application of causal mapping is always positioned somewhere in between the articulation of knowledge and formulation of planning, using what one knows and actionable implementation. Causal maps, as representations of interview material, cannot possibly capture fully the interviewee's understanding of the problem that is being researched. However, with appropriate research design and execution, interview material can be just good enough to engage in useful theorizing. Thereby causal maps, as tools designed for emergent exploration of the questions of interest, can be drawn upon to learn more about the interview material that is available.

\section{REFERENCES}

Ackermann, F., \& Alexander, J. 2016. Researching complex projects: Using causal mapping to take a systems perspective. International Journal of Project Management, 34(6): 891-901.

Ackermann, F., \& Eden, C. 2005. Using Causal Mapping with Group Support Systems to Elicit an Understanding of Failure in Complex Projects: Some Implications for Organizational Research. Group Decision and Negotiation, 14(5): 355-376.

Ackermann, F., \& Eden, C. 2011 1a. Making Strategy: Mapping Out Strategic Success. London, UK: Sage.

Ackermann, F., \& Eden, C. 2011b. Negotiation in Strategy Making Teams: Group Support Systems and the Process of Cognitive Change. Group Decision and Negotiation, 20(3): 293-314.

Ackermann, F., \& Eden, C. 2011c. Strategic Management of Stakeholders: Theory and Practice. Long Range Planning, 44(3): 179-196.

Ackermann, F., Eden, C., \& Cropper, S. 1990. Cognitive mapping - a user's guide. Glasgow, UK: University of Strathclyde.

Ackermann, F., Eden, C., \& Pyrko, I. 2016. Accelerated Multi-Organization Conflict Resolution. Group Decision and Negotiation, 25(5): 901-922.

Ackermann, F., Eden, C., Williams, T., \& Howick, S. 2007. Systemic Risk Assessment: A Case Study. The Journal of the Operational Research Society, 58(1): 39-51.

Ackermann, F., Franco, L. A., Gallupe, B., \& Parent, M. 2005. GSS for Multi-Organizational Collaboration: Reflections on Process and Content. Group Decision and Negotiation, 14(4): 307-331.

Ackermann, F., Howick, S., Quigley, J., Walls, L., \& Houghton, T. 2014. Systemic risk elicitation: Using causal maps to engage stakeholders and build a comprehensive view of risks. European Journal of Operational Research, 238(1): 290-299.

Alvesson, M. 2003. Beyond Neopositivists, Romantics, and Localists: A Reflexive Approach to Interviews in Organizational Research. The Academy of Management Review, 28(1): 13-33. 
Alvesson, M. 2011. Interpreting interviews. London, UK: SAGE.

Armstrong, T., \& Eden, C. 1979. An Exploration of Occupational Role: An Exercise in Team Development. Personnel Review, 8(1): 20-23.

Atkinson, P., \& Silverman, D. 1997. Kundera's Immortality: The Interview Society and the Invention of the Self. Qualitative Inquiry, 3(3): 304-325.

Biernacki, P., \& Waldorf, D. 1981. Snowball Sampling: Problems and Techniques of Chain Referral Sampling. Sociological Methods \& Research, 10(2): 141-163.

Boje, D. M. 1995. Stories of the Storytelling Organization: A Postmodern Analysis of Disney as "TamaraLand". The Academy of Management Journal, 38(4): 997-1035.

Boje, D. M. 2003. Using narratives and telling stories. In D. Holman, \& R. Thorpe (Eds.), Management and Language. London, UK: Sage.

Bonarius, H., Holland, R., \& Rosenburg, S. 1981. Personal Construct Psychology. London, UK: Macmillan.

Bourne, H., \& Jenkins, M. 2005. Eliciting Managers' Personal Values: An Adaptation of the Laddering Interview Method. Organizational Research Methods, 8(4): 410-428.

Brown, S. M. 1992. Cognitive mapping and repertory grids for qualitative survey research: some comparative observations. Journal of Management Studies, 29(3): 287-307.

Bryson, J. M., Ackermann, F., \& Eden, C. 2014. Visual Strategy: Strategy Mapping for Public and Nonprofit Organizations. San Francisco, CA, USA: John Wiley \& Sons.

Bryson, J. M., Ackermann, F., Eden, C., \& Finn, C. B. 2004. Visible Thinking - Unlocking Causal Mapping for Practical Results. Chichester, UK: John Wiley \& Sons.

Chia, R., \& Holt, R. 2009. Strategy without Design. Cambridge, UK: Cambridge University Press.

Clarkson, G. P., \& Hodgkinson, G. P. 2005. Introducing CognizerTM: A Comprehensive Computer Package for the Elicitation and Analysis of Cause Maps. Organizational Research Methods, 8(3): 317-341.

Cropper, S., Eden, C., \& Ackermann, F. 1990. Keeping Sense of Accounts Using Computer-Based Cognitive Maps. Social Science Computer Review, 8(3): 345-366.

Cunliffe, A. 2003. Reflexive Inquiry in Organizational Research: Questions and Possibilities. Human Relations, 56(8): 983-1003.

Cunliffe, A. 2008. Discourse Analysis. In R. Thorpe, \& R. Holt (Eds.), The SAGE Dictionary of Qualitative Management Research. London, UK: Sage.

Cunliffe, A. 2011. Crafting Qualitative Research:Morgan and Smircich 30 Years On. Organizational Research Methods, 14(4): 647-673.

de Geus, A. 1988. Planning as learning. Harvard Business Review (March-April): 70-74.

Dundon, T., \& Ryan, P. 2010. Interviewing Reluctant Respondents: Strikes, Henchmen, and Gaelic Games. Organizational Research Methods, 13(3): 562-581.

Easterby-Smith, M., Thorpe, R., \& Jackson, R. P. 2015. Management \& Business Research (5th edition ed.). London, UK: Sage.

Easterby-Smith, M., Thorpe, R., \& Holman, D. 1996. Using repertory grids in management. Journal of European Industrial Training, 20(3): 3-30.

Eden, C. 1988. Cognitive mapping. European Journal of Operational Research, 36(1): 1-13.

Eden, C. 1992a. One the nature of cognitive maps. Journal of Management Studies, 29(3): 261-265.

Eden, C. 1992b. Strategy development as a social process. Journal of Management Studies, 29(6): 799812.

Eden, C. 1994. Cognitive mapping and problem structuring for system dynamics model building. System Dynamics Review, 10(2-3): 257-276.

Eden, C. 2004. Analyzing cognitive maps to help structure issues or problems. European Journal of Operational Research, 159(3): 673-686.

Eden, C., \& Ackermann, F. 2000. Mapping Distinctive Competencies: A Systemic Approach. The Journal of the Operational Research Society, 51(1): 12-20.

Eden, C., \& Ackermann, F. 2001. Group Decision and Negotiation in Strategy Making. Group Decision and Negotiation, 10(2): 119-140. 
Eden, C., \& Ackermann, F. 2006. Where next for problem structuring methods. Journal of the Operational Research Society, 57(7): 766-768.

Eden, C., \& Ackermann, F. 2010. Competences, distinctive competences, and core competences. In R. Sanchez, A. Heene, \& T. E. Zimmermann (Eds.), A Focussed Issue on Identifying, Building, and Linking Competences (Research in Competence-Based Management, , Vol. 5: 3-33: Emerald Group Publishing Limited.

Eden, C., Ackermann, F., \& Cropper, S. 1992. The analysis of cause maps. Journal of Management Studies, 29(3): 309-324.

Eden, C., \& Huxham, C. 1996. Action Research for Management Research. British Journal of Management, 7(1): 75-86.

Eden, C., \& Huxham, C. 2001. The Negotiation of Purpose in Multi-Organizational Collaborative Groups. Journal of Management Studies, 38(3): 373-391.

Eden, C., \& Huxham, C. 2002. Action Research. In D. Partington (Ed.), Essential Skills for Management Research.: 254-271. London, UK: SAGE.

Eden, C., \& Jones, S. 1984. Using Repertory Grids for Problem Construction. The Journal of the Operational Research Society, 35(9): 779-790.

Eden, C., Jones, S., \& Sims, D. 1983. Messing about in problems. Oxford, England: Pergamon Press.

Eden, C., Jones, S., Sims, D., \& Smithin, T. 1981. The intersubjectivity of issues and issues of intersubjectivity. Journal of Management Studies, 18(1): 37-47.

Feldman, M. S. 2004. Resources in Emerging Structures and Processes of Change. Organization Science, 15(3): 295-309.

Franco, L. A., \& Rosenhead, J. 2001. The role of Wide-band GDSS in increasing value for multiorganisational groups: the case of the UK construction industry. Paper presented at the Group Decision and Negotiation Conference, Delft, The Netherlands.

Fransella, F., \& Bannister, D. 1977. A Manual for Repertory Grid Technique. London, UK: Academic Press.

Gherardi, S. 2012. How to conduct a practice-based study: problemas and methods. Cheltenham, UK: Edward Elgar Publishing

Gioia, D. A., Corley, K. G., \& Hamilton, A. L. 2013. Seeking Qualitative Rigor in Inductive Research:Notes on the Gioia Methodology. Organizational Research Methods, 16(1): 15-31.

Gioia, D. A., \& Pitre, E. 1990. Multiparadigm Perspectives on Theory Building. Academy of Management Review, 15(4): 584-602.

Hadjimichael, D. 2017. Haridimos Tsoukas: Understanding Organizational Change Via Philosophy and Complexity. In D. B. Szabla, W. A. Pasmore, M. A. Barnes, \& A. N. Gipson (Eds.), The Palgrave Handbook of Organizational Change Thinkers: 1355-1371. Cham, Switzerland: Springer International Publishing.

Hernes, T. 2014. A process theory of organization. Oxford, UK: Oxford University Press.

Hibbert, P., Siedlok, F., \& Beech, N. 2016. The Role of Interpretation in Learning Practices in the Context of Collaboration. Academy of Management Learning \& Education, 15(1): 26-44.

Hodgkinson, G. P., Maule, A. J., \& Bown, N. J. 2004. Causal Cognitive Mapping in the Organizational Strategy Field: A Comparison of Alternative Elicitation Procedures. Organizational Research Methods, 7(1): 3-26.

Howick, S., \& Eden, C. 2001. The impact of disruption and delay when compressing large projects: going for incentives? Journal of the Operational Research Society, 52(1): 26-34.

Huff, A. S. 1990. Mapping Strategic Thought. New York, NY, USA: Wiley.

Jackson, K. M., \& Trochim, W. M. K. 2002. Concept Mapping as an Alternative Approach for the Analysis of Open-Ended Survey Responses. Organizational Research Methods, 5(4): 307-336.

Jenkins, M. 2002. Cognitive Mapping. In D. Partington (Ed.), Essential Skills for Management Research.: 254-271. London, UK: SAGE.

Kelly, G. 1955. The Psychology of Personal Constructs. New York, NY, USA: Norton. 
Langley, A. 2015. Developing cumulative knowledge about strategy as practice. In D. Golsorkhi, L. Rouleau, D. Seidl, \& E. Vaara (Eds.), Cambridge Handbook of Strategy as Practice, 2nd ed. Cambridge, UK: Cambridge University Press.

Laukkanen, M. 1994. Comparative Cause Mapping of Organizational Cognitions. Organization Science, 5(3): 322-343.

Mittereder, F., Durow, J., West, B. T., Kreuter, F., \& Conrad, F. G. 2017. Interviewer-respondent Interactions in Conversational and Standardized Interviewing. Field Methods, 0(0).

Nicolini, D. 1999. Comparing Methods for Mapping Organizational Cognition. Organization Studies, 20(5): 833-860.

Nicolini, D. 2013. Practice Theory, Work, and Organization: An Introduction. Oxford, UK: Oxford University Press.

Paroutis, S., Franco, L. A., \& Papadopoulos, T. 2015. Visual Interactions with Strategy Tools: Producing Strategic Knowledge in Workshops. British Journal of Management, 26: S48-S66.

Phillips, N., Sewell, G., \& Jaynes, S. 2008. Applying Critical Discourse Analysis in Strategic Management Research. Organizational Research Methods, 11(4): 770-789.

Polanyi, M. 1966. The logic of tacit inference Philosophy, 41(155): 1-18.

Pratt, M. G. 2009. From the Editors: For the Lack of a Boilerplate: Tips on Writing Up (and Reviewing) Qualitative Research. Academy of Management Journal, 52(5): 856-862.

Pyrko, I., Dörfler, V., \& Eden, C. 2017. Thinking together: What makes Communities of Practice work? Human Relations, 70(4): 389-409.

Pyrko, I., Howick, S., \& Eden, C. 2017. Risk Systemicity and City Resilience, EURAM Conference. Glasgow, UK.

Saunders, M. N. K., Lewis, P., \& Thornhill, A. 2015. Research Methods for Business Students (7th ed.). Harlow, UK: Pearson.

Saunders, M. N. K., \& Townsend, K. 2016. Reporting and Justifying the Number of Interview Participants in Organization and Workplace Research. British Journal of Management, 27(4): 836-852.

Shaw, D., Ackermann, F., \& Eden, C. 2003. Approaches to sharing knowledge in group problem structuring. J Oper Res Soc, 54(9): 936-948.

Shaw, D., Smith, C. M., \& Scully, J. 2017. Why did Brexit happen? Using causal mapping to analyse secondary, longitudinal data. European Journal of Operational Research, 263(3): 1019-1032.

Siedlok, F., Hibbert, P., \& Sillince, J. 2015. From practice to collaborative community in interdisciplinary research contexts. Research Policy, 44(1): 96-107.

Swan, J. 1997. Using Cognitive Mapping in Management Research: Decisions about Technical Innovation. British Journal of Management, 8(2): 183-198.

Tavella, E., \& Franco, L. A. 2015. Dynamics of Group Knowledge Production in Facilitated Modelling Workshops: An Exploratory Study. Group Decision and Negotiation, 24(3): 451-475.

Teddlie, C., \& Yu, F. 2007. Mixed Methods Sampling: A Typology With Examples. Journal of Mixed Methods Research, 1(1): 77-100.

Weick, K. E. 1995. Sensemaking in Organizations. Thousand Oaks, CA, USA: Sage Publications.

Wenger, E. 1998. Communities of Practice: Learning, meaning and identity. Cambridge, UK: Cambridge University Press.

Williams, T., Ackermann, F., \& Eden, C. 2003. Structuring a delay and disruption claim: An application of cause-mapping and system dynamics. European Journal of Operational Research, 148(1): 192204.

Winnicott, D. W. 1953. Transitional objects and transitional phenomena; a study of the first not-me possession. The International Journal of Psych-Analysis, 34(2): 89-97.

Wright, R. P. 2008. Eliciting Cognitions of Strategizing Using Advanced Repertory Grids in a World Constructed and Reconstructed. Organizational Research Methods, 11(4): 753-769. 


\section{Figures}

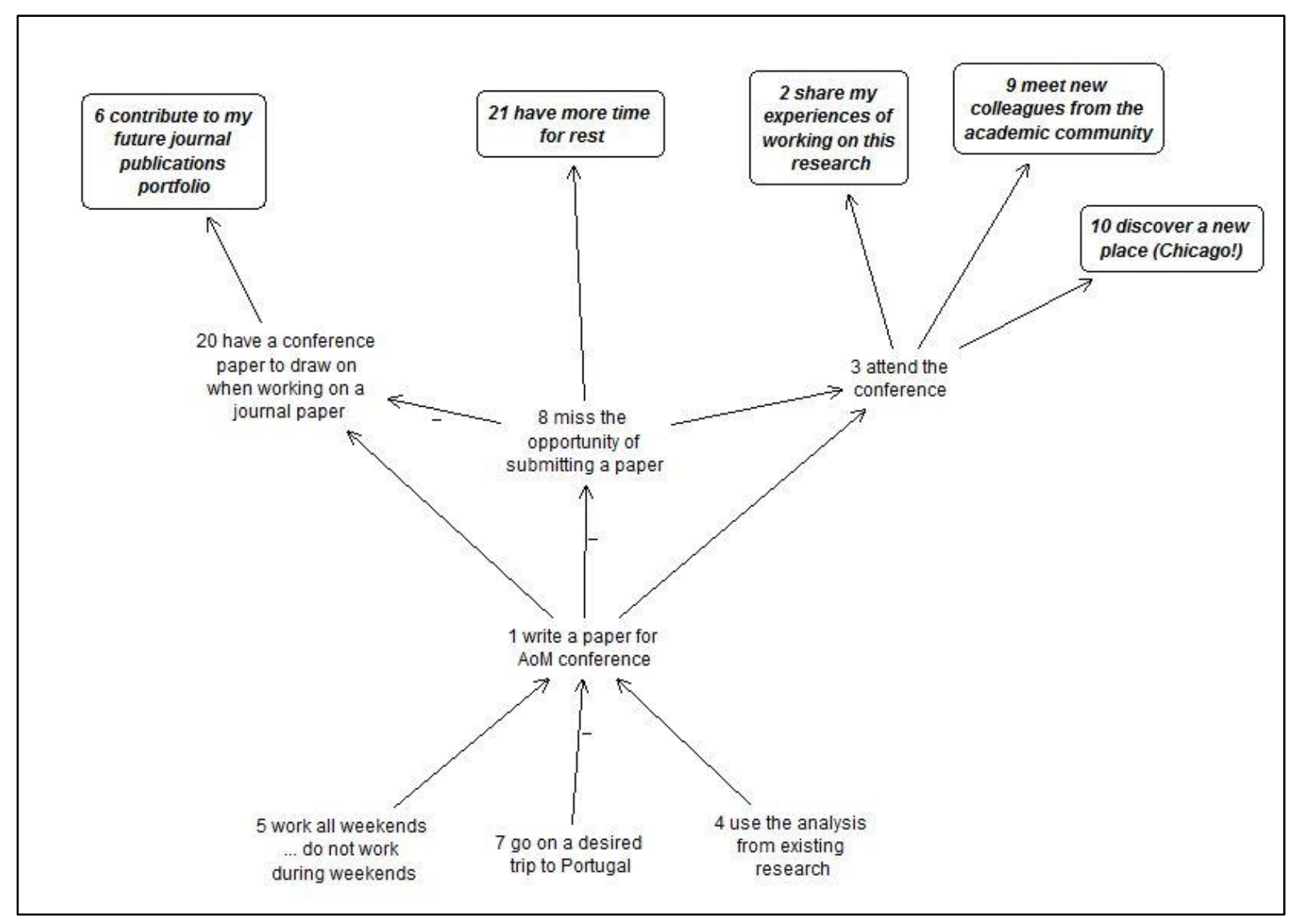

Figure 1: Example of a cognitive map

*LEGEND: Statements in borders are general outcomes, whilst all other statements are 'standard' concepts. Numbers before statements signify the order in which the statements were added on the map. Links signify 'may lead to' relationships. Negative links with a minus sign (e.g. links going from statements 7 and 1) signify 'may not lead to' relationships. The three dots in statement 5 signify 'rather than' - thus showing two opposing poles of that statement. 


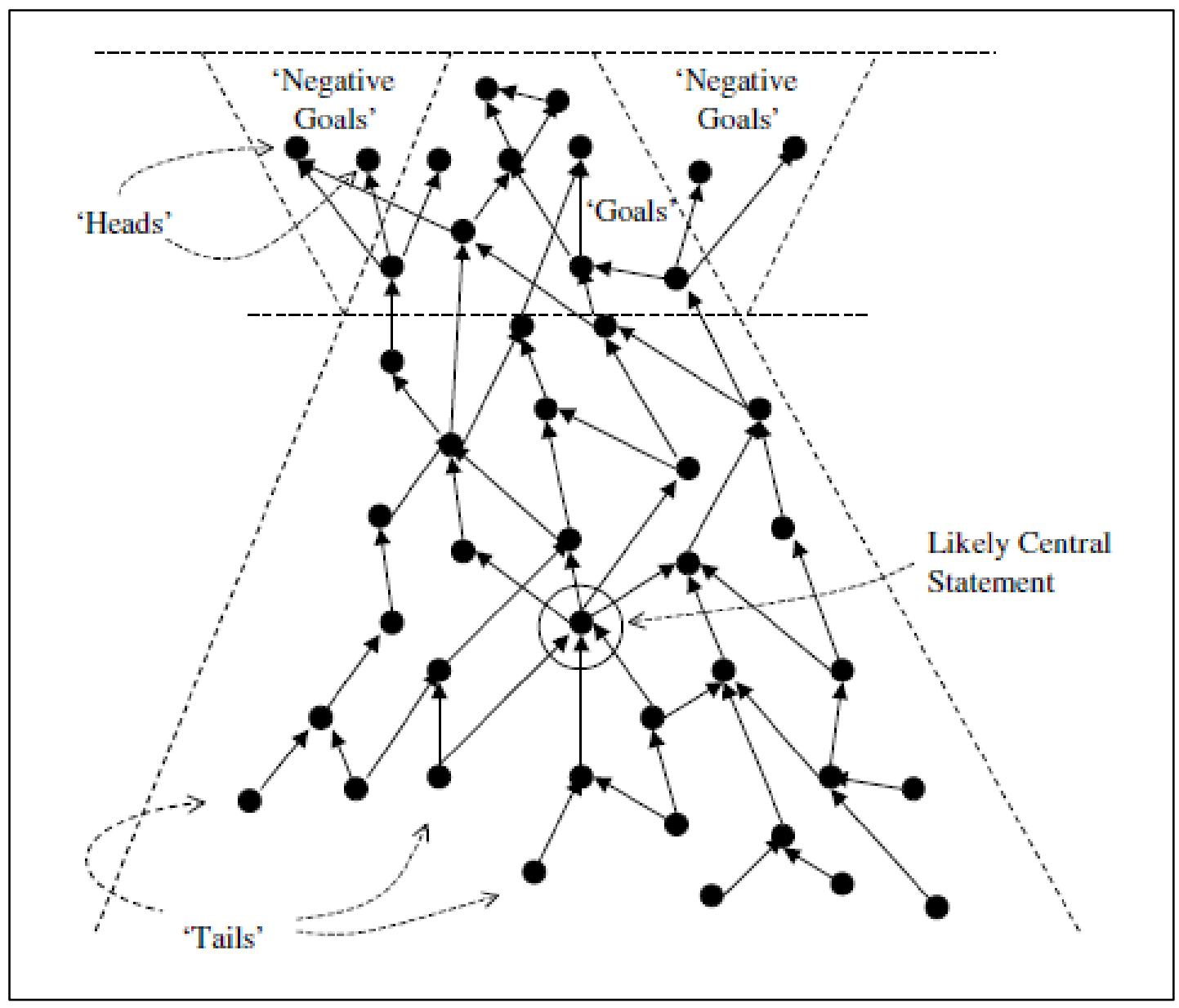

Figure 2: The 'teardrop' structure of a causal map. Source: (Eden, 2004: 676). 


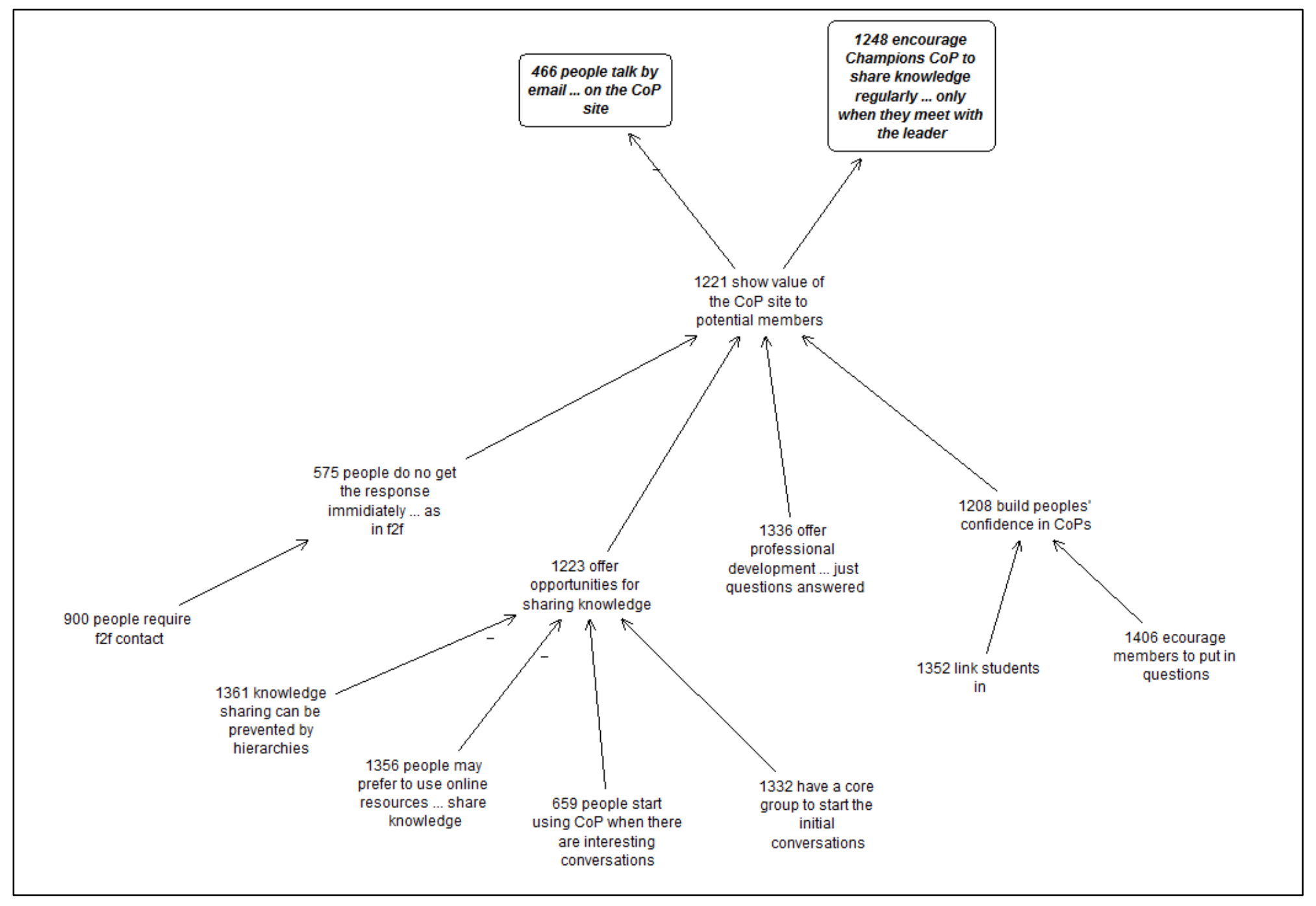

Figure 3: A segment of a mapped interview 


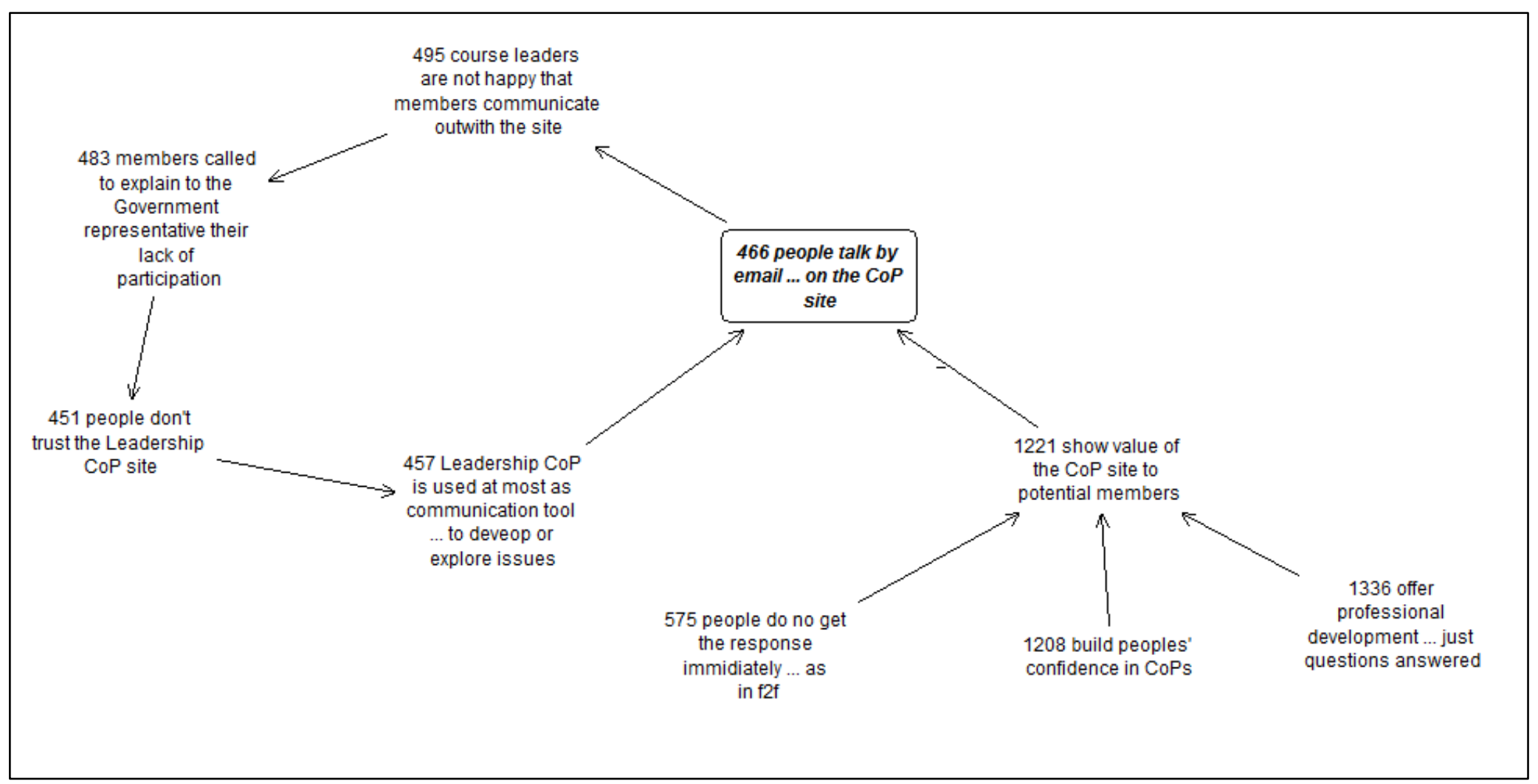

Figure 4: Example of a feedback loop 